Article

\title{
Process Design Aspects for Scandium-Selective Leaching of Bauxite Residue with Sulfuric Acid ${ }^{\dagger}$
}

\author{
Konstantinos Hatzilyberis * (iD), Theopisti Lymperopoulou, Lamprini-Areti Tsakanika, \\ Klaus-Michael Ochsenkühn, Paraskevas Georgiou (iD, Nikolaos Defteraios, Fotios Tsopelas and \\ Maria Ochsenkühn-Petropoulou *
}

School of Chemical Engineering (Chem. Eng.), National Technical University of Athens (NTUA), 9 Iroon Polytechniou St., 15780 Athens, Greece; veralyb@chemeng.ntua.gr (T.L.); btsakanika@gmail.com (L.-A.T.); klausochsenkuehn@yahoo.com (K.-M.O.); pngche@gmail.com (P.G.); deftereosn@tee.gr (N.D.); ftsop@central.ntua.gr (F.T.)

* Correspondence: ksh@chemeng.ntua.gr (K.H.); oxenki@central.ntua.gr (M.O.-P.); Tel.: +30-210-772-3300 (K.H.); +30-210-772-3094 (M.O.-P.)

† This paper is the written, extended and updated version of the oral presentation entitled as "Design Aspects of a Selective Leaching Process for Scandium Recovery from Bauxite Residue", in the ERES 2017 Conference (European Rare Earth Resources 2017), which was held in Santorini, Greece, 28-31 May 2017. Abstract and Presentation are available online at: http:/ / eres2017.eresconference.eu/program/ (accessed on 23 January 2018); Hatzilyberis, K.; Lymperopoulou, T.; Tsakanika, L.-A.; Ochsenkuehn, K.; Georgiou, P.;

Ochsenkuehn-Petropoulou, M. Design Aspects of a Selective Leaching Process for Scandium Recovery from Bauxite Residue. Book of Abstracts of ERES 2017 Conference (European Rare Earth Resources 2017), Santorini, Greece, 28-31 May 2017; Track 4: Rare Earth Elements from secondary resources, pp. 188-189.

Received: 11 January 2018; Accepted: 21 February 2018; Published: 25 February 2018

\begin{abstract}
Aiming at the industrial scale development of a Scandium (Sc)-selective leaching process of Bauxite Residue (BR), a set of process design aspects has been investigated. The interpretation of experimental data for Sc leaching yield, with sulfuric acid as the leaching solvent, has shown significant impact from acid feed concentration, mixing time, liquid to solids ratio $(L / S)$, and number of cycles of leachate re-usage onto fresh BR. The thin film diffusion model, as the fundamental theory for leaching, either with constant particle size for selective leaching, or with shrinking particle size for less- or non-selective leaching, interprets the relevant experimental data. In both cases, a concept for an unyielding core supplements the basic model. Especially for the selective leaching mild conditions, the simplest model version agrees with the experiments, since both prove 1st order kinetics, while for extreme conditions, a combined conversion rate model with diffusion and chemical reaction inside particles is proposed. The maximization of Sc recovery per unit of consumed solvent emerged as highly critical for the process economics.
\end{abstract}

Keywords: Scandium; REEs; bauxite residue; selective leaching; process design aspects; thin film diffusion model; unyielding core; specific recovery

\section{Introduction}

Sc is a commercially rare and expensive metal [1] with increasing applications in advanced technology, especially in: Solid Oxide Fuel Cells (SOFCs) [2]; advanced technology sensors [3]; applications of advanced Al-Sc alloys [2,4-8] in automotive, aeronautical and transportation industries; 3D printing techniques [9]; and a wide range of applications in optical and electronic industries [10].

European Commission's classification of Critical Raw Materials (CRMs) [11] ranks Sc as critically high on supply risk and on economic importance (2017) due to the dwindling of available stockpiles combined with the globally limited production [12] and the evolution of new applications [2-10,13-16]. 
Sc is not, indeed, a rare element in nature, but it is a very rarely concentrated element, particularly over $100 \mathrm{~g} / \mathrm{t}$ in non-radioactive minerals, making commercially usable deposits of this critical material very rare [17]. Therefore, global deposits of Sc-rich residues from mineral industry, such as phosphoric ore, rare earth ore residue, bauxite ore, zirconium ore, can be exploited for Sc recovery ([18-23] and Table S1 of Supplementary Materials) and establishment of a stable Sc supply route [5]. The exploitation of BR from the aluminum industry, as a resource for production of Sc and other Rare Earth Elements (REEs), such as $\mathrm{Y}$ and lanthanides, emerges as a well promising perspective in the metallurgical processes $[2,4,5]$. This is fully aligned with the European Union's target for sustainable access to CRMs as being of high importance for economy, competitiveness and the environmental protection $[5,11,24]$.

In this context, the Greek BR is evaluated as a resource for an economically viable recovery of Sc [5,25-31]. Greek BR, with an average Sc concentration ca. $120 \mathrm{~g} / \mathrm{t}$ (dry basis) [25,28-30], can be considered as a valuable Sc resource as it is comparable to the globally exploitable Sc secondary resources ([18-23] and Table S1 of Supplementary Materials). Greek BR is a byproduct of Aluminum of Greece (AoG) industry, producing about 750,000 t BR annually [32]. Wet BR is a highly alkaline and very fine grained slurry, consisting mainly of $\mathrm{Fe}, \mathrm{Ca}$ and $\mathrm{Al}$ compounds, accompanied by numerous valuable trace elements such as V, Cr, Zn, Ga, Nb, Zr, Ta, lanthanides, Y and Sc [25,28-30]. REEs are at a concentration of about $1 \mathrm{~kg} / \mathrm{t}$ dry BR, with less than $10 \%$ variation for an over $25-y e a r$ investigation $[25,28,30]$.

Hydrometallurgical treatment is the most commonly used technique for REEs recovery from BR [33]. Current industrially applied hydrometallurgical treatments for Sc recovery usually involve mineral acids with strong conditions [18,34], or especially for BR, an alkaline solvent method is also used [23]. However, alkaline solvents do not favor some of the most advanced methods [5] of (following the leaching) Resin Ion Exchange (RX) and Solvent liquid-liquid Extraction (SX), for Sc enrichment and purification. Nanofiltration [5] as well as leaching with ionic liquids [5,35] are under investigation, although ionic liquids are quite expensive.

An integrated process for the selective recovery, and purification of Sc and other REEs, from BR using hydrometallurgical leaching, RX and SX, has been developed and optimized in laboratory (lab.) and batch-type pilot plant scale [25-31]. The research focused on maximum Sc recovery combined with minimum dissolution of main elements and especially Fe since it hinders the following purification steps. Nitric acid $\left(\mathrm{HNO}_{3}\right)$ was selected as leaching solvent since it showed the best recovery and selectivity of Sc over Fe ([28,30] and Table S2 of Supplementary Materials). However, nitric acid $\left(\mathrm{HNO}_{3}\right)$ shows inadequate compliance with EU environmental regulations for waste solids disposal and significantly higher operating cost. Therefore, sulfuric acid $\left(\mathrm{H}_{2} \mathrm{SO}_{4}\right)$ was studied as an acidifying and leaching solvent.

The present work investigates a design aspect set [36] for the specific leaching process with focus on the recovery of Sc. This investigation has been based on a preliminary, for the context of [5], experimental data set from Greek BR leaching exclusively with $\mathrm{H}_{2} \mathrm{SO}_{4}$ solutions, which has been partially presented by the authors in $[5,30,36]$.

The proposed design model can sufficiently predict the economic viability of this process, especially if it is taken into account that the viability depends substantially on the composite maximization of Sc recovery per unit of consumed acid, and not on the simpler of the standalone quantified recovery.

Although, the main purpose for the development of this design aspects set is to be used in the process scaling-up for demonstration and industrial application [5], as well as in the consequent process and quality control, the research contribution of the entire work is a combination of an experimental method with a prediction model that both together could be exploitable, either directly or after appropriate modification, for any leaching process targeting a trace metal in a mineral. 


\section{Materials and Methods}

\subsection{Characterization of the Raw Material (BR)}

The used BR sample was produced in December 2016 and provided by AoG, Viotia, Greece. Sc content was determined to be $105 \mathrm{~g} / \mathrm{t}$ (dry basis), moisture content 26\% $w / w$ and $\mathrm{pH}=11.3$. The chemical composition of the main compounds of Greek BR, as well as the values of physical properties, is reported elsewhere [28-30,37].

\subsection{Experimental Method}

\subsubsection{Reagents}

Leaching experiments were conducted using sulfuric acid $96-98 \% w / w$ of industrial grade from raw chemicals market. Stock standard solutions for Sc (single element solution $1000 \mathrm{mg} / \mathrm{L}$ ) by Fluka Chemie GmbH (Buchs, Switzerland) and for main elements (multi element solution for ICP $1000 \mathrm{mg} / \mathrm{L}$ ) by Merck KGaA (Darmstadt, Germany) were used for ICP-OES calibration.

\subsubsection{Instrumentation}

All the samples were analyzed for Sc $(361.383 \mathrm{~nm})$ and Fe $(259.939 \mathrm{~nm})$ by ICP-OES Optima 7000DV, Perkin Elmer (Waltham, MA, USA). A magnetic stirring heating plate HeiTec and a mechanical stirrer Hei-Torque 100, Heidolph (Schwabach, Germany) were used for agitation (700-1000 rpm). pH measurements were carried out with a pH-meter multi 350i, by WTW (Weilheim, Germany). The particle size distribution was measured by a Malvern Mastersizer micro with laser diffraction [29].

\subsubsection{Analytical Procedure}

BR leaching was performed under different conditions. Variables such as acid concentration, $L / S$ ratio, temperature, as well as multistage leaching procedure (multiple use of acid) were tested and optimized. Magnetic and/or mechanical stirring was applied. After leaching, all samples were centrifuged and the supernatant liquid was filtered under vacuum. Final $\mathrm{pH}$ was measured and the samples were stored for analysis. For multistage leaching procedure (simulation of PLS reflux in industrial scale) the first leaching stage was conducted and after centrifuging the collected liquid was re-used for leaching of a fresh BR sample at the same conditions. The whole procedure was repeated thrice.

\subsection{Arithmetical Methods of Data Processing}

Data from kinetic experiments has been statistically processed to be fit on 1st order kinetics. The proposed method is detailed in Supplementary Materials, Text S1. The result of this interpretation method is an explicit function of Sc leaching yield with feed acid concentration and mixing time.

Data from solvent excess $(L / S)$ experiments have been processed with a well-known method for optimization of non-linear functions (i.e., Newton method with central differentiation scheme). More specifically, the optimized values for the correlation parameters were determined through the minimization of the statistical residual sum of squares $\left(\mathrm{SS}_{\mathrm{res}}\right)$ between the predicted values from the proposed function and the respective data.

\section{Results (Design Aspects)}

Lab. scale experiments on $\mathrm{Sc}$ leaching yield with $\mathrm{H}_{2} \mathrm{SO}_{4}$ have shown detectable impact only from the following parameters:

- $\quad$ Mixing time, especially for values $<1 \mathrm{~h}$

- Acid feed concentration and the dependent $\mathrm{pH}$ value of the leachate

- $L / S$ ratio, at the leaching reactor feed 
- Number of cycles of the same leachate re-using onto fresh BR batches

Regarding the rest of the parameters, they did not show any significant Sc yield variation within the range of Sc-selective conditions, such as: (i) Temperature effect for the investigated range (ambient $-80{ }^{\circ} \mathrm{C}$ ), but with taking into account that increasing temperature up to $80{ }^{\circ} \mathrm{C}$ resulted in enhanced Fe dissolution, rendering the process non selective; (ii) Particle size, as dry BR is a material with exclusively fine particles; (iii) Different agitation modes proved not to have a detectable effect. Relevant experimental studies $[28,29,31,34]$, considering a variety of acids and conditions, show similar results.

\subsection{Kinetics (Mixing Time Impact)}

Concerning process kinetics investigation, Figure 1 shows the variation of Sc yield (mg · Sc in the leachate $/ \mathrm{mg} \cdot \mathrm{Sc}$ in the dry BR feed) with mixing residence time under different concentrations of sulfuric acid solutions, constant $L / S=50$ and sufficient agitation. The appended graph in Figure 1 supports the hypothesis of 1st order kinetics by presenting three characteristic examples of Sc-selective leaching conditions with the adaptation of experimental data to be highly sufficient (large values of $R^{2}$ ), given that dry BR is a fine powder with significantly variable Sc concentration in the micro-structure ([37] (pp. 52-53), [38]).
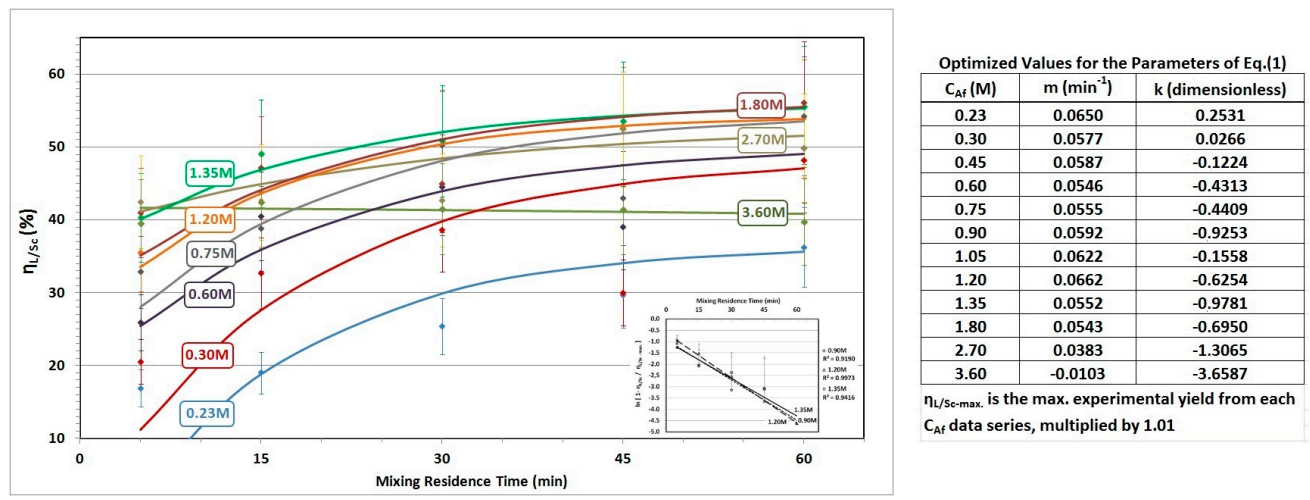

Figure 1. Variation of Sc leaching yield $\left(\eta_{L / S c}\right)$ with mixing residence time and feed acid (sulfuric) concentration under constant $L / S=50$. The colored curves show 1st order kinetics fittings to the relevant experimental data $\left[\eta_{L / S c}=\eta_{L / S c-\max }\left(1-\mathrm{e}^{-m t+k}\right)\right]$. Appended graph: logarithmically linearized 1st order kinetics, in terms of Sc leaching yield, for three feed acid concentrations.

The 1st order kinetic approach for leaching is in accordance with a conditional version of the general diffusion mechanism (i.e., thin film model) as seen in [39], (Equation (2) of [31]), and Supplementary Materials, Text S2. Integrating the thin film equation (Equation (S1) of Supplementary Materials) with mixing duration $t(\mathrm{~min})$, constant values of the diffusion coefficient $k^{\prime}$, the mass exchange surface to film width ratio $(A / b)$, and the liquid volume $V$, as well as with a constant time-average Sc concentration of the saturated solution in contact with the particles $\left(\overline{C_{S}}\right)$, gives: $c=\overline{c_{S}} \cdot\left(1-\mathrm{e}^{-\frac{k \prime}{V} \cdot(A / b) \cdot\left(t-t_{0}\right)}\right)$.

According to following definitions: $c=\frac{\eta_{L / S c} \cdot M_{d} \cdot C_{\mathrm{Sc} / \mathrm{BR}}}{V}, L / S=V / M_{d}, S=A / M_{d}, K_{L}=k^{\prime} / b$ (i.e., $K_{L} S=$ const.), the above equation is transformed to: $\eta_{L / S c}=\frac{\overline{c_{S}} \cdot(L / S)}{C_{S c / B R}} \cdot\left(1-\mathrm{e}^{-\frac{K_{L} S}{(L / S)} \cdot\left(t-t_{0}\right)}\right)$.

After naming: $\eta_{L / S c-\max }=\frac{\overline{C_{S}} \cdot(L / S)}{C_{S c / B R}}, m=\frac{K_{L} \cdot S}{(L / S)}$, and $k=m t_{0}$, the resultant equation form is: $\eta_{L / S c}=\eta_{L / S c-\max } \cdot\left(1-\mathrm{e}^{-m \cdot t+k}\right)$

With acid feed concentration $\left(C_{A f}\right)$ being an experimental parameter for $\eta_{L / S_{c}}, \eta_{L / S_{c}-\max ,}, m$ and $k$, the general form of equation becomes:

$$
\eta_{L / S c}\left(C_{A f}, t\right)=\eta_{L / S c-m a x}\left(C_{A f}\right) \cdot\left(1-\mathrm{e}^{-m\left(C_{A f}\right) \cdot t+k\left(C_{A f}\right)}\right)
$$


The extra term $k$ corrects the uncertainty of Sc yield at leaching start, especially for stronger feed acid solutions where the assumption $(t=0, c=0)$ seems not to be valid. $\eta_{L} / S_{c}-$ max. is not a regression parameter, but either an experimental value, or a simple interpolation between the nearest experimental values. By using the proposed method of Supplementary Materials, Text S1, the correlation parameters $\eta_{L / S c-m a x}, m$ and $k$ are converted to concentration-dependent functions, meaning that the unknown dependencies of $\overline{c_{s}}, K_{L} S$, and $t_{0}$ with $C_{A f}$ are quantified.

Figure 2 proves that the best linearity $\left(R^{2} \rightarrow 1\right)$, or equivalently the best fitting to 1 st order kinetics, occurs at these acid feed concentrations where the leaching process has experimentally shown the best selective behavior to a trace element as Sc (yields up to 60\%), while main element yields, and especially that of $\mathrm{Fe}$, remain low ( $<4 \%$ for $\mathrm{Fe}$ ). Under less- or non-Sc-selective leaching conditions, deviations from 1st order kinetics could be explained by the BR particle size decay during leaching, as an effect of enhanced and rapid main element dissolution (e.g., for upper concentrations range and for mixing time beyond the kinetic effects, sieving analysis demonstrated that the volume moment mean $D[4,3]$ was approximately $40 \mu \mathrm{m}$ before leaching process, while after leaching was reduced to approximately $20 \mu \mathrm{m})$. Deviations from predictions of Equation (1) during a kinetic experiment are quantified as: $\Delta \eta_{R M S}=s \cdot\left[1-G\left(C_{A f}\right)\right]^{0.5}$, with the distribution among $\overline{c_{S}}, K_{L} S$ and $t_{0}$ to not be determinable from the available experimental data.

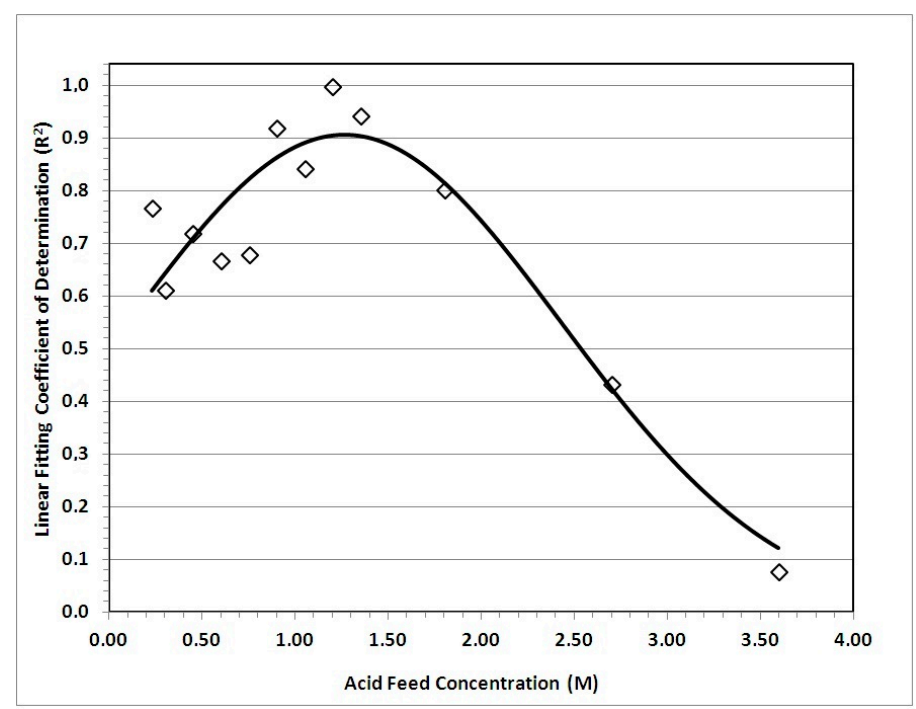

Figure 2. Variation of the linear fitting coefficient of determination $\left(R^{2}\right)$ of linearized 1st order kinetics with acid feed concentration $\left(C_{A f}\right)$, for the Sc leaching kinetics experiments of Figure 1 (BR leaching with sulfuric acid solution, at $L / S=50$ ). Solid line: Optimized fitting of a general Gaussian function, $G\left(C_{A f}\right)=a \times \exp \left(-b\left(C_{A f}-\mu\right)^{2}\right)$, where $a=0.905, b=0.3673 \mathrm{M}^{-2}$, and $\mu=1.267 \mathrm{M}$.

\subsection{Solvent Excess (L/S) Impact}

Using the Fick's second law in the context of the simple thin film diffusion model (Supplementary Materials, Text S2 and Equation (5) of [31]), the equation is formulated as below:

$$
\eta_{L / S c}=c_{S} \cdot \frac{L / S}{C_{S c / B R}} \cdot\left(1-\mathrm{e}^{-\frac{K_{L} S \tau}{L / S}}\right)
$$

The assumptions of Equation (2) are:

(i) The diffusion coefficient $k^{\prime}\left(\right.$ in $K_{L}\left(=k^{\prime} / b\right)$ ) is taken as approximately constant [39], by only varying $L / S$.

(ii) The ratio $A / b$ remains constant with processing time by simultaneous proportional variation of both $A$ and $b$ (see Supplementary Materials, Text S2), or otherwise the product of the 
overall mass transfer coefficient with the specific surface area $K_{L} S=\left(k^{\prime} / b\right)\left(A / M_{d}\right)=\left(k^{\prime} / M_{d}\right)(A / b)$ remains constant.

(iii) The mixing residence time is constant $(\tau=60 \mathrm{~min}$ ) for the entire set of Solvent Excess experiments.

A re-arrangement of Equation (2), in which mixing time is beyond the time range of substantial kinetics effects, gives Equation (3):

$$
\eta_{L / S c}(L / S)=c_{S}^{*} \cdot \frac{L / S}{C_{S c / B R}} \cdot\left(1-q^{\frac{1}{L / S}}\right)
$$

where $c_{S}{ }^{*}$ and $q$ are regression parameters directly connected to the respective physical magnitudes of Equation (2).

Figure 3a shows the best fitting of Equation (3) to a typical variation of Sc yield with $L / S$ ratio for given feed acid concentration and residence time, while Figure $3 b$ depicts a similar result for a combined range of $L / S$ ratio and feed acid concentration $\left(C_{A f}\right)$. The interpretation of the last graph (for a given $L / S$ ratio and a mixing residence time) shows the limited effect of feed acid concentration on Sc yield which is comparable to the experimental fluctuations caused by the high variability of Sc content in the raw BR microstructure. In accordance with Figure 3b, the theoretical model for the impact of solvent excess (Equations (2) and (3)) does not directly involve the feed acid concentration.

On the other hand, the time range of substantial kinetic effects seems to be essentially dependent on feed acid concentration. For lower acid concentrations $(<0.3 \mathrm{M})$, it is particularly long, for medium acid concentrations (0.3-3 M), it seems to be relatively concentration-invariant, and for higher concentrations $(>3 \mathrm{M})$, it is extremely short (Figure 1). Concerning the medium feed acid concentrations zone, any experimentally observed fluctuations of Sc yield for long mixing time values and given $L / S$ are within the experimental error (Figures 1 and 3 ), and theoretically they are absorbed by the calculation of a common set of regression parameters $\left(c_{s}^{*}, q\right)$ in Equation (3). However, in case of a combination of Equations (1) and (3) in a unified correlation, a secondary type of variability for $\eta_{L / S c}$ with $C_{A f}$, will be introduced for long mixing times and given $L / S$, by the term $\eta_{L / S c-\max }\left(C_{A f}\right)$ of Equation (1).

Using the median value of $C_{S c / B R}=97 \mathrm{~g} / \mathrm{t}$, the proposed model gives: $c_{S}{ }^{*}=12.8 \mathrm{mg} / \mathrm{L}$, while for the over the years' average $C_{S c / B R} \approx 120 \mathrm{~g} / \mathrm{t}$, the same fitting gives: $c_{S}{ }^{*}=15.8 \mathrm{mg} / \mathrm{L}$. In both cases Equation (3) gives: $q=0.045$, and assuming a constant value $S=10 \mathrm{~m}^{2} / \mathrm{g}$ [37] (pp. 52-53), then $K_{L}=-\ln q / S \tau \approx 5.17 \times 10^{-8} \mathrm{dm} / \mathrm{min}$.

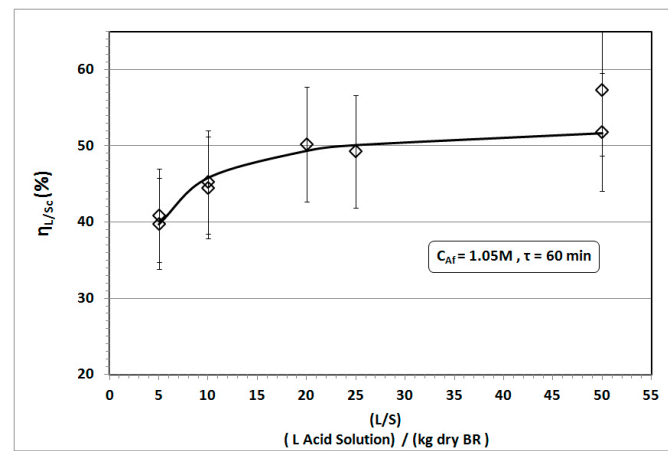

(a)

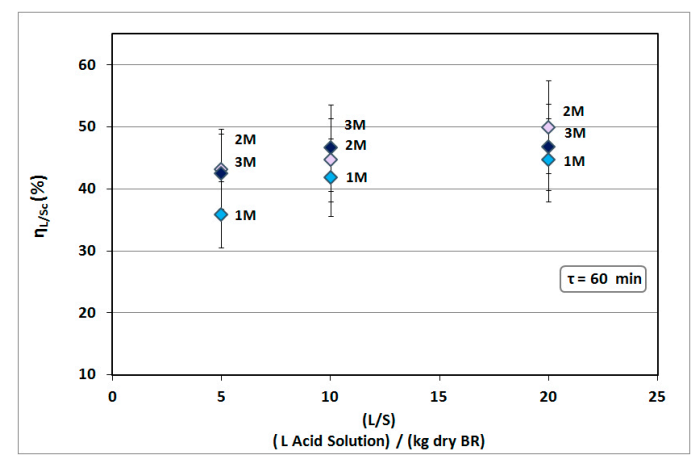

(b)

Figure 3. (a) Variation of Sc leaching yield $\left(\eta_{L / S c}\right)$ with $L / S$ ratio, for feed acid (sulfuric) concentration $C_{A f}=1.05 \mathrm{M}$, for constant mixing residence time $\tau=60 \mathrm{~min}$, mechanical stirring, ambient conditions, and $C_{S c / B R}=97 \mathrm{~g} / \mathrm{t}$ (Solvent Excess data Series). Solid line is optimized fitting of Equation (3); (b) Variation of $\eta_{L / S c}$ with $L / S$ for 3 different feed acid (sulfuric) concentrations (1, 2 and $3 \mathrm{M}$ ), under conditions of (a).

In a respective Greek BR leaching study with nitric acid, where $C_{S c / B R} \approx 120 \mathrm{~g} / \mathrm{t}$, a similar fitting of this model (to the experimental data) has given $c_{S}{ }^{*}=15.0 \mathrm{mg} / \mathrm{L}$ [31]. Comparing $c_{S}{ }^{*}$ values for sulfuric 
and nitric acid, under the same Sc concentration in raw BR, indicates that $c_{S}{ }^{*}$ for Sc is approximately constant, characteristic of BR, and probably independent from the kind of strong mineral acid. The Sc concentration in the leachate of a selective BR leaching process could not be expected to outreach $c_{S}{ }^{*}$ and this prediction is of critical importance for the following RX process.

\subsection{Chemical Reaction Impact (pH of Leachate)}

The final $\mathrm{pH}$ of leachate solution has been verified to be dependent on the acid feed characteristics, namely on the acid feed concentration as depicted in Figure $4 \mathrm{a}$, and on the $L / S$ ratio, as shown in Figure $4 b$.

Figure 4 a shows that concentration of acidic leachate varies linearly with the concentration of acidic feed, under kinetically neutral conditions $(t \geq 1 \mathrm{~h})$. The extent of partial neutralization of acid gives the chemically equivalent consumption of BR alkaline content, which is calculated as concentration difference between acid feed and leachate $\left(C_{A f}-C_{A}\right)$, multiplied by the leachate volume and dissociated $\mathrm{H}^{+}$per molecule of consumed $\mathrm{H}_{2} \mathrm{SO}_{4}$. The variation of $C_{A f}-C_{A}$, for constant leaching volume and BR quantity among the experiments of Figure $4 \mathrm{a}$, proves that the neutralization of BR is partial and approximately proportional to acid feed concentration $\left(C_{A f}\right)$. Figure $4 \mathrm{~b}$ shows that $C_{A}$ increases with solvent excess $(L / S)$ causing a non-linear impact on the process economics.

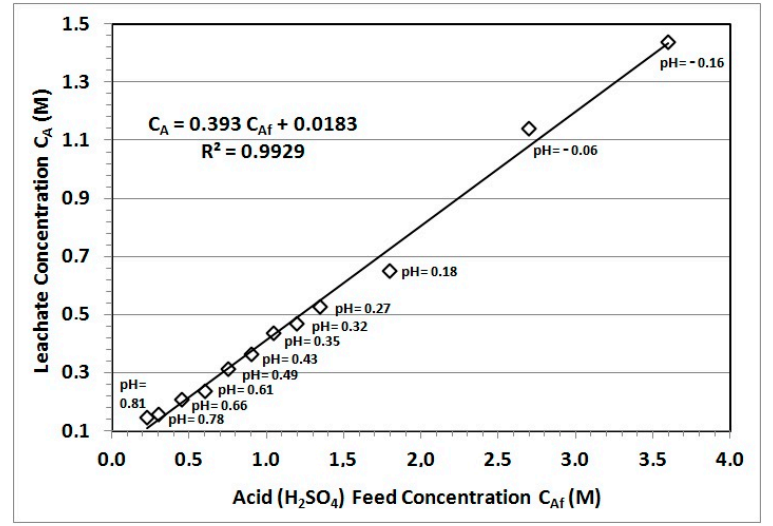

(a)

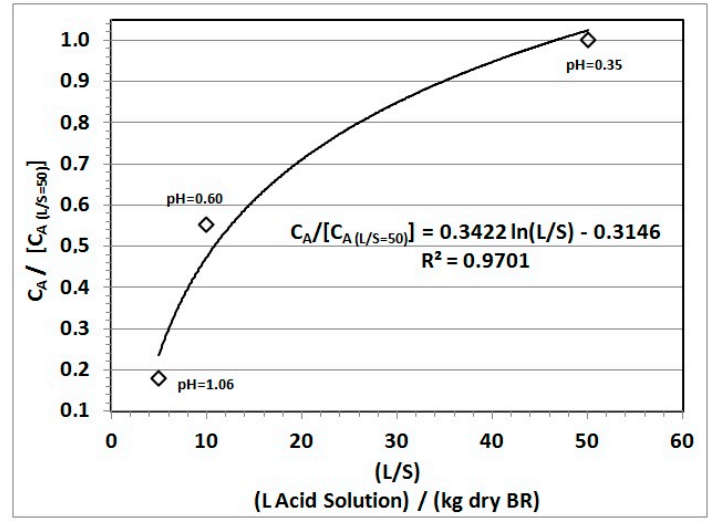

(b)

Figure 4. (a) Variation of leachate acid concentration $(M)$ with feed acid (sulfuric) concentration, for constant $L / S=50(\mathrm{~L} / \mathrm{kg}), \tau=60 \mathrm{~min}$, mechanical stirring and ambient conditions. The equation of LSRL fitting, $R^{2}$ and the respective measured $\mathrm{pH}$ values are appended. $C_{A}$ has been calculated from $\mathrm{pH}$ with use of $p K_{a 1}=-3$ and $p K_{a 2}=1.99 ;(\mathbf{b})$ Variation of leachate acid concentration with $L / S$, as fraction of the respective concentration at $L / S=50$, when feed acid concentration is $1.05 \mathrm{M}$ and under conditions of (a). Equation of ln-LSR fitting, $R^{2}$ and the respective $\mathrm{pH}$ values are appended.

\subsection{Leachate Recycling Impact}

\subsubsection{Specific Recovery and Process Economics}

The key variable for the economic viability of the leaching process is specific recovery, which is expressed in $\mathrm{mg}$ of leached Sc per L of consumed acidic solvent, for a given acid feed concentration (Table 1). Maximization of specific recovery means the maximum possible Sc quantity to be recovered (i.e., turnover maximization), with the minimum possible consumption of acid solvent (i.e., main cost minimization). Specific recovery calculation can be extended to the case of multiple use of the same quantity of acidic solvent onto fresh BR batches, by PLS recycling, as well as to the case of possible re-usage of recovered acidic solvent from the RX process (Table 1). 
Table 1. Definitions of Specific Recovery for the Acidic Leaching of the Greek BR.

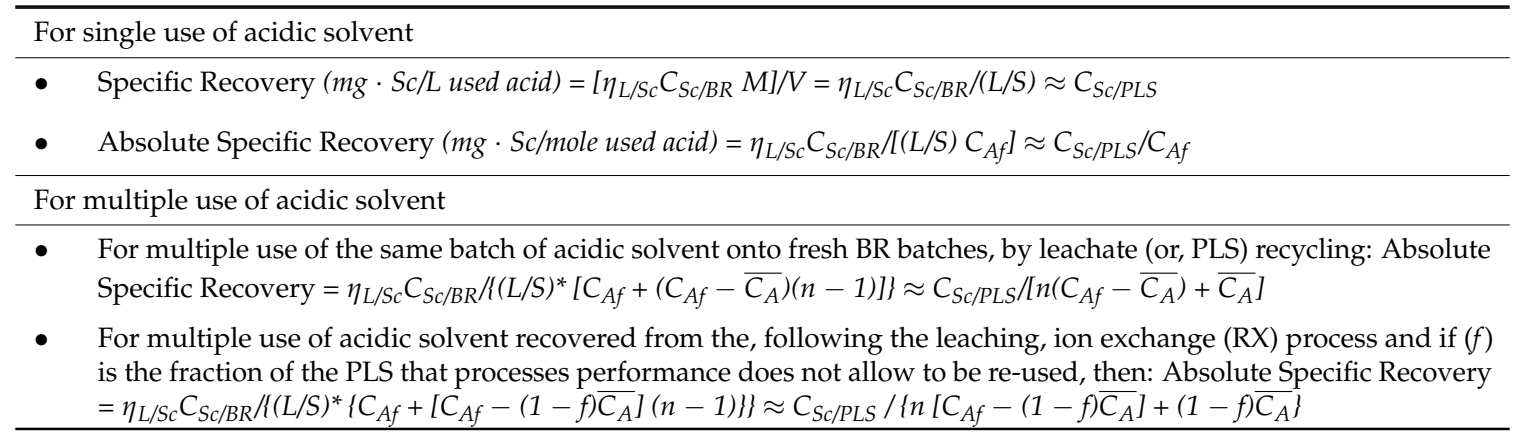

Specific recovery is directly proportional to the leaching yield and to the Sc content of BR; in inverse proportion to $L / S$ ratio, and to the total acid consumption as concentration difference ( $\geq 60 \%$ from Figure 4); and finally, it is proportional to Sc concentration in the PLS. Experiments showed that Sc yield divided by $L / S$ ratio follows the exponential decay curve appearing in Figure 5.

Both the low $L / S$ and the increase of the cumulative Sc yield by recycling of the acidic solvent favor the specific recovery and consequently the process economics. The multiple use of the PLS onto fresh BR led to outstanding leaching performance with Sc concentration to approach $8 \mathrm{mg} / \mathrm{L}$, so exceeding the results obtained by selective leaching with single acid in $[30,31,34]$. Even higher Sc concentrations could be achieved but at a very low $L / S$ ratio where the gel formation effect remains an issue to be confronted [40].

A process economic analysis with integrated design aspects showed that:

- Market competitive operation starts when capacity exceeds a lower boundary ( $t \mathrm{BR} /$ day)

- Economic viability is particularly sensitive to the cost of the concentrated acid

- Unit cost depends substantially on the Sc concentration in the PLS, or the specific recovery

- $\quad$ Sc content in the BR and water consumption have impact on process economics.

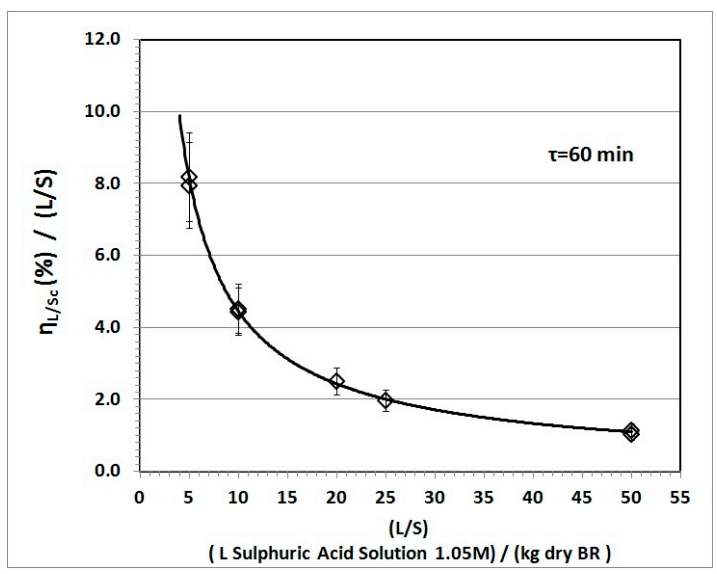

Figure 5. Variation of the $\eta_{L / S c}(\%) /(L / S)$ with $L / S$ ratio, for $C_{A f}=1.05 \mathrm{M}, \tau=60 \mathrm{~min}$, mechanical stirring, and ambient conditions.

Furthermore, a process viability analysis with integrated design aspects showed the following:

- Market competitive operation starts at a minimum plant capacity $(t \mathrm{BR} /$ day)

- The economic viability is particularly sensitive to the cost of the consuming concentrated acid

- The unit cost depends substantially on the Sc concentration in the PLS, or the specific recovery

- The Sc content in the BR and the water consumption have, also, an impact on the process economics. 


\subsubsection{A Unified Mathematical Expression for the Sc Leaching Yield}

An attempt to combine kinetics with the solvent excess model is based on the common, for both experimental sets, $L / S=50$ measurements. The kinetics of Sc yield predictions could be multiplied by the variation of Sc yield with $L / S$, when it is expressed as fraction of the $L / S=50 \mathrm{Sc}$ yield, and as long as the assumption of a uniform mode of $S c$ yield variation with $C_{A f}$ and $t$ for different $L / S$ values, is approximately valid. The unified correlation for Sc yield of BR leaching is presented in Equation (4):

$$
\eta_{L / S c}\left(C_{A f}, t, L / S\right)=\operatorname{Kinetics}\left(C_{A f}, t, L / S=50\right) \cdot \frac{\text { Solvent Excess } \eta_{L / S c} \text { variation }\left(C_{\mathrm{Af}}=1.05 \mathrm{M}, \tau=60 \mathrm{~min}, L / S\right)}{\eta \exp . \text { from Solvent Excess Series } \mid C_{\mathrm{Af}}=1.05 \mathrm{M}, \tau=1.05 \mathrm{M}, L / S=50}
$$

or, with use of Equations (1) and (3):

$$
\eta_{L / S c}\left(C_{A f}, t, L / S\right)=\eta_{L / S c-\max }\left(C_{A f}\right) \cdot\left(1-e^{-m\left(C_{A f}\right) \cdot t+k\left(C_{A f}\right)}\right) \cdot \frac{(L / S) \cdot C_{S}{ }^{*}\left(C_{S c / B R}\right)}{\eta_{\max } \cdot C_{S c / B R}} \cdot\left(1-q^{\frac{1}{L / S}}\right)
$$

Investigation of specific recovery limits with recycling of leachate onto fresh BR led to the collection of experimental data that allowed verification, generalization and fine-tuning of Equation (4). The generalized unified Equation (5) with $(L / S)^{*}$ ratio referring to leachate recycling, or of RX acid by-product re-using, is constructed incorporating a set of deviation correction terms $\left(\Delta \eta, C_{0}, p\right)$ to improve its predictability.

$$
\eta_{L / S c}\left(C_{A f}, t,(L / S)^{*}\right)=\Delta \eta+\left(\frac{C_{A f}}{C_{0}}\right)^{p} \cdot \eta_{L / S c-\max }\left(C_{A f}\right) \cdot\left(1-e^{-m\left(C_{A f}\right) \cdot t+k\left(C_{A f}\right)}\right) \cdot \frac{(L / S)^{*} \cdot c_{\mathcal{C}}^{*}\left(C_{S c / B R}\right)}{\eta_{\max } \cdot C_{S c / B R}} \cdot\left(1-q^{\frac{1}{(L / S)^{*}}}\right)
$$

Figure 6 shows a comparison between experimental yields and theoretical predictions, for experiments with up to three times of leachate recycling. The fitting performance of the initial unified correlation (4) appears in Figure 6a, while Figure 6b shows the application of the generalized and fine-tuned correlation (5).

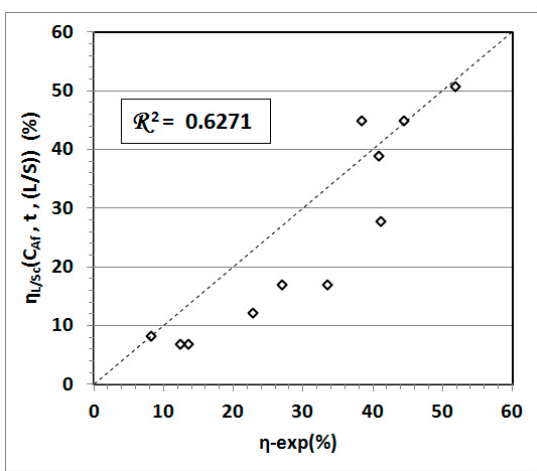

(a)

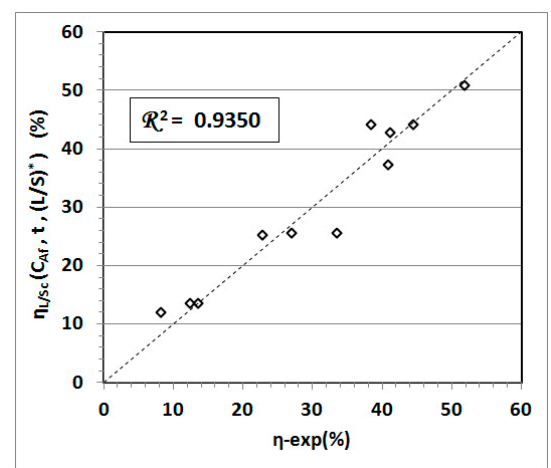

(b)

Figure 6. (a) Comparison between experimental values for Sc yield and respective theoretical predictions of Equation (4), for $\tau=60 \mathrm{~min}, C_{S c / B R}=97 \mathrm{~g} / \mathrm{t}$ and data collection from experiments with and without leachate recycling; (b) Comparison between the experimental data of (a) and the respective theoretical predictions of generalized Equation (5). The optimized deviation correction terms are: $C_{0}=1.65 \mathrm{M}, p=-0.315$, and $\Delta \eta=-7.67 \%$.

The significant improvement of theoretical predictability of Equation (5) was achieved with the contribution of the following corrective terms:

- $\left(\frac{C_{A f}}{C_{0}}\right)^{p}$ : It corrects the minor deviation from the assumption that regression parameters $\left(c_{S}^{*}, q\right)$ are constant for the entire set of the investigated leaching conditions. The use of a particular feed acid concentration $\left(C_{0}\right)$ to the uniform values of $c_{s}{ }^{*}$ and $q$, introduces concentration-dependent deviation from the uniformity. The negative optimized value for the exponent $p$ means higher deviations for lower feed acid concentrations, as a result of the long-lasting kinetic effects at this concentration zone (Figure 1 and Section 3.2). 
- $\Delta \eta$ : It allows correction of the systematic error in prediction of Sc yield. This kind of deviation is explained by possible incompatibilities between the different sets of experimental measurements exploited in Figure 6 data.

\section{Discussion}

\subsection{Evaluation of the Data Interpretation with the Thin Film Theory}

The interpretation of Sc yield data showed that a 1st order kinetic approach is sufficiently valid and accurate, especially for selective leaching conditions. The same theory was utilized to represent the impact of solvent excess, or $L / S$, to the Sc leaching yield, on condition that time variable $(t)$ is fixed and sufficiently long $[31,39]$.

Inquiring which of the real physical or chemical phenomena dominates the overall equivalent rate of the thin film model, the relative invariance of Sc yield with temperature, in the investigated range, seems to be the answer, meaning that the process activation energy is extremely low. This fact implies either a well catalyzed chemical reaction, including the case of a spontaneous self-catalyzed reaction, that are phenomena usually irrelevant and rarely secondary to the general leaching process, or, quite more appropriately, it implies dominance of solids-fluid physical transport phenomena. Therefore, the dominant process mechanism seems to be the low resistance ion-diffusion [41] to a BR particle.

\subsection{Model Extensions}

Significant deviations from single diffusion may appear if a concentrated leaching pulp is involved in the process $[5,40]$. To cover these cases, an extension of the diffusion theoretical approach is proposed. This relates to the additional participation of the un-reacted shrinking core model from chemical reaction engineering; either with its typical form for approximately constant external surface area of the particles, or with a modified form inside a shrinking particle.

The chemical reactions of neutralization and complex formation between acid solvent and alkaline content of BR particles remain, generally, as a secondary rapid stage. At very low solvent excess $L / S$, the appearance of gel formation [40] indicates that the chemical reaction stage is expected to show non-negligible impact on the total rate, and the un-reacted shrinking core model seems to be the most suitable to equivalently describe the impedance from this additional effect (see Figure 7a).

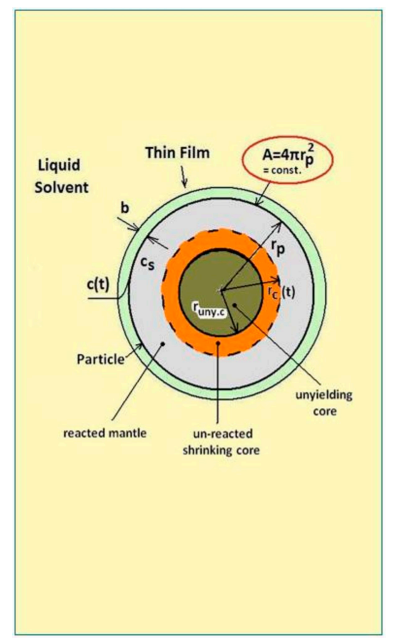

(a)

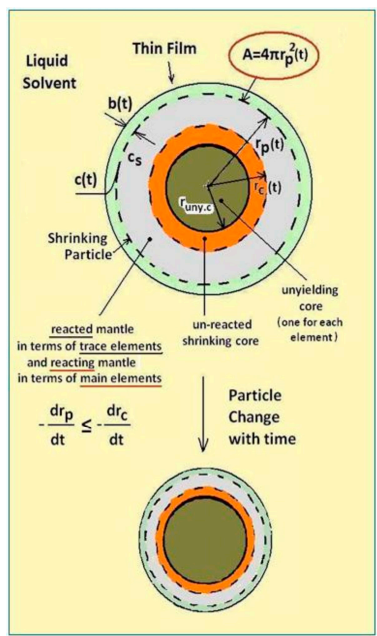

(b)

Figure 7. Visual representation of the proposed leaching model extension: (a) Selective to Trace Elements BR Leaching. Standard model: Thin Film Diffusion with constant particle external surface area $(A)$. For very low $L / S \leq 5: 1$ : Thin Film Diffusion is combined with the Un-Reacted Shrinking Core chemical reaction model; (b) Less-, or Non-, Selective to Trace Elements BR Leaching. General case: Thin 
Film Diffusion with time varying $A / b$ ratio. For very low $L / S$ : A proposed complex model of thin film diffusion with a surface-reacting shrinking particle for the main elements and an un-reacted shrinking core for the trace elements.

In case of less- or non-selective to trace elements conditions, the diffusion of cations has also to be combined with the chemical reactions effects, but in contrast to the selective leaching conditions, the external surface area of the particle decreases by time, as shown in Figure $7 \mathrm{~b}$. Then, the application of a complex model of a surface-reacting shrinking particle for the main elements, and simultaneously of an un-reacted shrinking core inside the shrinking particle for the trace elements, could be in effect.

The unyielding core concept is a supplement to the overall model of this work, valid at any leaching conditions. Evaluation of leaching yield data shows that the size of this residual core depends on the cationic element and leaching conditions. Moreover, studies of BR micro-structure [38] have shown that the residual content of trace elements is trapped in unyielding micro-cores inside the particle with bound main cationic elements, and mostly Fe ([23], heavily extractable Sc). However, the validity of the overall model extension set could be tested in a future study.

\section{Conclusions}

Greek BR can be considered as a valuable Sc resource, since Sc is a metal of increasing economic importance and simultaneously of increasing supply risk.

Analysis of the relevant experimental investigation with $\mathrm{H}_{2} \mathrm{SO}_{4}$ solutions has proven significant impact of Sc leaching yield from: acid feed concentration, mixing residence time, $L / S$ ratio at the process feed, and number of leachate re-using cycles onto fresh BR.

The thin film diffusion model, as the theoretical standard for the leaching process, either with constant particle size for selective leaching, or with shrinking particle size for less- or non-selective leaching, interprets sufficiently well the relevant experimental data. For selective leaching, the standard model agrees with the experiments, since both prove 1st order kinetics, but for conditions that include low solvent excess, the thin film diffusion model could perform better if it is to be combined with the un-reacted shrinking core chemical reaction model, or with a more complex model for extreme leaching conditions. Furthermore, a suitable explanation of the relevant experimental data shows that each element (cation) has its own size of an unyielding core inside the particle, which depends on leaching conditions. This core stands as a limit for the leaching yield and for the extension of the parallel chemical reactions.

Specific recovery (mg - Sc in PLS/consumed acid quantity) is the key variable for leaching process economics. It is directly proportional to the leaching yield and to the Sc content of BR. It is in inverse proportion to $L / S$ ratio and to the total acid consumption as concentration difference, and finally, it is proportional to Sc concentration in the produced solids-free PLS.

Supplementary Materials: The following are available online at http:/ / www.mdpi.com/2075-163X/8/3/79/s1, Text S1: Mathematical Method for the Interpretation of the Kinetic Experimental Data, Text S2: 1st Order Kinetics and Fundamentals of the Thin Film Theory, Table S1: Examples of Sc Concentration in global Resources being (or, to be) Industrially Exploited for Scandia (Sc oxide)/Sc Production, Table S2: Recovery of Sc and other REEs by mild leaching with different acids, Table S3: (a) Description of kinetic data processing in mathematical terms. (b) Scheme for a comprehensible visual presentation of kinetic data processing. (c) An example of calculations, Figure S1: A visual presentation of leaching process mechanism (a visual approach to the real diffusion mode and the equivalent of the thin film diffusion concept), and Equation (S1).

Acknowledgments: The research leading to these results has been performed within the SCALE project and received funding from the European Community's Horizon 2020 Programme (H2020/2014-2020), under Grant Agreement No. 730105. Moreover, SCALE project covers the cost to publish in open access. The authors, also, gratefully acknowledge the company II-VI Inc. (Saxonburg, PA, USA) for the fruitful collaboration and cooperation in the context of SCALE, as well as in a previous joint project. 
Author Contributions: This work has been derived with interdisciplinary collaboration between Departments of the NTUA School of Chemical Engineering, as the Department of Process Analysis and Plant Design (Konstantinos S. Hatzilyberis; Nikolaos Defteraios; Paraskevas N. Georgiou) and the Department of Chemical Sciences (Maria Ochsenkühn-Petropoulou; Theopisti Lymperopoulou, Lamprini-Areti Tsakanika, Fotios Tsopelas and Klaus-Michael Ochsenkühn). The members of the Department of Chemical Sciences designed and produced the main experimental background of this paper, which partially originates from a previously unpublished work. The members of the Department of Process Analysis and Plant Design performed analysis and interpretation of the experimental results in the context of theoretical principles of transport phenomena, of unit operations and of chemical reaction engineering. The writing of manuscript was implemented mainly by K.S. Hatzilyberis, with substantial contribution from all other authors.

Conflicts of Interest: Conflicts of Interest: The authors declare no conflict of interest. Moreover, it is elucidated that a part of the experimental background of this work has been derived in a joint project between NTUA and II-VI Inc. (Saxonburg, PA, USA): Utilization of Red Mud as Alternative Resource of Rare Earths (REEs), 2014-2016, Internal Reports (confidential unpublished data), under a funding contract with confidentiality terms, but also with possibility for publication after the approval from the funding sponsor (II-VI Inc.) for the kind of information to be publicly disseminated. II-VI Inc. agrees with the publication of this work and the particular indirect dissemination of its experimental background. Authors declare that the indirect publication of experimental results is limited to the marginally required extent for the scientific integrity of this paper. Also, the results of this work (design aspects) have been derived in the context of the SCALE project [5] and the decision to be published was a matter of collective agreement among the partners of the project consortium; Aluminium of Greece, Member of Mytilineos Group and II-VI Deutschland GmbH, subsidiary of II-IV Inc., are among the members of this consortium. The publication is in accordance with the terms of the SCALE Grant Agreement No. 730105 with the funding authority (EU/EASME). Finally, the funding sponsors had no role in the design of the study; in the collection, analyses, or interpretation of data, and in the writing of the manuscript.

\section{Abbreviations}

\begin{tabular}{|c|c|}
\hline$(a, b, \mu)$ & $\begin{array}{l}\text { regression parameters set for the general Gaussian function } G\left(C_{A f}\right) \text { of Figure 2, (dimensionless } \\
\left.R^{2}, \mathrm{M}^{-2}, \mathrm{M}\right)\end{array}$ \\
\hline$A$ & total area of the solids-liquid interface in the leaching mixture, $\left(\mathrm{dm}^{2}\right)$ \\
\hline$b$ & ffective thickness of the liquid film surrounding the particles, $(\mathrm{dm})$ \\
\hline$C$ & $\begin{array}{l}\text { concentration }(w / v) \text { of the solute (here, Sc) in the bulk of the solution at time } t,(\mathrm{mg} \cdot \mathrm{Sc} / \mathrm{L} \text { of } \\
\text { acidic leachate) }\end{array}$ \\
\hline$C_{0}$ & constant feed acid concentration in the corrective factor $\left(\frac{C_{A f}}{C_{0}}\right)^{p}$ of Equation (5), (M) \\
\hline$C_{A}$ & $\begin{array}{l}\text { nominal acid concentration in the leachate that is calculated from measured } p H,(\mathrm{M}) \\
\text { average acid concentration in the leachate after } \mathrm{n} \text { times of leachate (or, PLS) re-usage for }\end{array}$ \\
\hline$\overline{C_{A}}$ & leaching of fresh BR batches, or $\overline{C_{A}}=\frac{1}{n-1} \sum_{i=1}^{n-1} C_{A_{i}}$, (M) \\
\hline$C_{A f}$ & acid feed concentration, as a variable, (M) \\
\hline$C_{A f^{*}}$ & acid feed concentration, as a discrete value (M) \\
\hline$c_{S}$ & $\begin{array}{l}\text { concentration }(w / v) \text { of the solute (here, } \mathrm{Sc}) \text { in the saturated solution in contact with the } \\
\text { particles, during leaching kinetics effects, }(\mathrm{mg} \cdot \mathrm{Sc} / \mathrm{L} \text { acidic leachate);it has the meaning of Sc } \\
\text { concentration in a solution of the leaching solvent, where the being dissolved BR matter is at } \\
\text { solubility levels }\end{array}$ \\
\hline$\overline{c_{S}}$ & $\begin{array}{l}\text { time average concentration }(w / v) \text { of the solute }(\text { here, } \mathrm{Sc}) \text { in the saturated solution in contact } \\
\text { with the particles, during leaching kinetics effects, }(\mathrm{mg} \cdot \mathrm{Sc} / \mathrm{L} \text { acidic leachate) }\end{array}$ \\
\hline$c_{S}^{*}$ & $\begin{array}{l}\text { regression variable of Equation (3), which is corresponding to the } c_{s} \text { parameter of Equation (2) } \\
\text { when mixing time exceeds the period of leaching kinetic effects, }(\mathrm{mg} \cdot \mathrm{Sc} / \mathrm{L} \text { acidic leachate) }\end{array}$ \\
\hline$C_{S c / B R}$ & Sc concentration $(w / w)$ in dry BR solids, $(\mathrm{mg} \cdot \mathrm{Sc} / \mathrm{kg}$ dry BR) \\
\hline$C_{S C / P L S}$ & $\begin{array}{l}\text { Sc concentration }(w / v) \text { in the PLS, }(\mathrm{mg} \cdot \mathrm{Sc} / \mathrm{L} \text { PLS) } \\
\text { diffusion coefficient in the leaching mixture (it is approximately equal to the product of the }\end{array}$ \\
\hline$k^{\prime}$ & $\begin{array}{l}\text { liquid-phase diffusivity } D_{L} \text { and the ratio of the total molar concentration of solvent and solute } \\
\text { to the logarithmic mean value of the solute concentration at each side of the thin film), } \\
\left(\mathrm{dm}^{2} / \mathrm{min}\right)\end{array}$ \\
\hline$K_{L}\left(=k^{\prime} / b\right)$ & $\begin{array}{l}\text { overall mass transfer coefficient for diffusion of Sc ions from BR particles to the liquid phase, } \\
(\mathrm{dm} / \mathrm{min})\end{array}$ \\
\hline
\end{tabular}


$L / S \quad$ inside the reactant leaching mixture, since the volume of the liquid part of the reactant leaching mixture has been experimentally found to be approximately equal to the volume of the fed acid, $L / S=V / M_{d},(\mathrm{~L}$ acid $/ \mathrm{kg}$ dry BR $)$

$(L / S)^{*} \quad$ a modified $L / S$ for cases of solvent recycling, which is equal to $(L / S) /$ (times of acidic solvent re-usage), or $(L / S)^{*}=(L / S) / n$, (L acid / $\mathrm{kg}$ dry BR)

$M \quad$ mass of the solute (here, Sc) transferred in time $\mathrm{t}$ to the liquid solvent, (mg $\cdot \mathrm{Sc})$

$M_{d} \quad$ total mass of dry BR particles in the leaching mixture, $(\mathrm{kg})$

$n \quad$ times of leachate (or, PLS) re-usage for leaching of fresh BR batches, (dimensionless)

$N \quad$ number of experimental data in a series

$p \quad$ exponent in the corrective factor $\left(\frac{C_{A f}}{C_{0}}\right)^{p}$ of Equation (5), (dimensionless)

q regression variable of Equation (3), that is corresponding to the term $e^{-K L S \tau}$ of Equation (2),

and where $-\ln q=K_{L} S \tau$ has units $(\mathrm{L} / \mathrm{kg})$

$R^{2} \quad$ the linear fitting coefficient of determination, $R^{2}=1-\left(\right.$ linear $\left.S S_{r e s}\right) / S S_{t o t}$, (dimensionless)

$R^{2} \quad$ the general fitting coefficient of determination, $R^{2}=1-S S_{\text {res }} / S S_{\text {tot }}$, (dimensionless)

$S$

$S$

coefficient that is dependent on $S S_{t o t}$ of each kinetic experiment of Figure $2\left(=\left(S S_{t o t}\right)^{0.5} / \mathrm{N}\right)$

$(\mathrm{mg} \cdot \mathrm{Sc}$ in the leachate $/ \mathrm{mg} \cdot \mathrm{Sc}$ in the dry BR feed)

specific surface area of dry BR particles participating in the leaching process, which is

$S\left(=A / M_{d}\right)$, if we define in the leaching process as mass exchange area the total surface area of a particle, external and internal (i.e., including pores surface area), $\left(\mathrm{dm}^{2} / \mathrm{kg}\right)$

$\mathrm{SS}_{\text {res }} \quad$ the statistical residual sum of squares, for predicted values by a given correlation, $(\mathrm{mg} \cdot \mathrm{Sc}$ in the leachate $/ \mathrm{mg} \cdot \mathrm{Sc}$ in the dry BR feed) $)^{2}$

the total sum of squares, for the experimental data set, $(\mathrm{mg} \cdot \mathrm{Sc}$ in the leachate $/ \mathrm{mg} \cdot \mathrm{Sc}$ in the dry BR feed $)^{2}$

$S S_{\text {tot }}$

$t$

V

mixing residence time of the leaching process, as a variable, (min)

the volume of acid fed in the leaching reactor, or approximately the liquid volume of the leaching mixture, $(\mathrm{L})$

Greek Letters

$\Delta \eta \quad$ corrective addend of Equation (5), ( $\mathrm{mg} \cdot \mathrm{Sc}$ in the leachate $/ \mathrm{mg} \cdot \mathrm{Sc}$ in the dry BR feed)

$\Delta \eta_{R M S} \quad$ root mean square of deviations between predicted and experimental values of a data series

$\eta_{L / S c} \quad$ leaching fractional yield for Sc; cumulative yield for multi-stage leaching, (mg · Sc in the leachate/ $\mathrm{mg} \cdot \mathrm{Sc}$ in the dry BR feed)

the maximum of $\eta_{L / S c}$ in Equation (1) for certain value of acid feed concentration $\left(C_{A f}\right)$; it represents the experimental yield value for infinite mixing period, and it is assumed here to be

$\eta_{L / S c-m a x} . \quad 1 \%$ more than the experimental value for 60 min mixing time, for logarithmization purposes, ( $\mathrm{mg} \cdot \mathrm{Sc}$ in the leachate $/ \mathrm{mg} \cdot \mathrm{Sc}$ in the dry BR feed)

experimental leaching yield for Sc from Solvent Excess Series when $C_{A f}=1.05 \mathrm{M}, \tau=60 \mathrm{~min}$,

$\eta \max$ and $L / S=50$, which is multiplied by 1.01, and used in Equations (4) and (5), (mg $\cdot \mathrm{Sc}$ in the leachate $/ \mathrm{mg} \cdot \mathrm{Sc}$ in the dry BR feed)

$\tau$ mixing residence time of the leaching process, as a discrete value, (min)

\section{References}

1. Mineral Prices, Rare Earth Metals. Available online: http://mineralprices.com/default.aspx\#rar (accessed on 23 January 2018).

2. Duyvesteyn, W.P.C.; Putnam, G.F. EMC Metals Corporation, White Paper. SCANDIUM: A Review of the Element, Its Characteristics, and Current and Emerging Commercial Applications. May 2014. Available online: http:/ / www.scandiummining.com/i/pdf/Scandium-White-PaperEMC-Website-June2014-.pdf (accessed on 23 January 2018).

3. Wang, Q.; Lu, Y.; Mishin, S.; Oshmyansky, Y.; Horsley, D.A. Design, fabrication, and characterization of scandium aluminum nitride-based piezoelectric micromachined ultrasonic transducers. J. Microelectromech. Syst. 2017, 26, 1132-1139. [CrossRef] 
4. UC RUSAL Sustainability Report 2016. Scientific and Technological Development. Available online: http: //sr.rusal.com/company-management-system/scientific-and-technical-development.php (accessed on 23 January 2018).

5. Project SCALE: Production of Scandium Compounds and Scandium Aluminum Alloys from European Metallurgical by-Products. European Community's Horizon 2020 Programme. Available online: http: / / cordis.europa.eu/project/rcn/206331_en.html (accessed on 23 January 2018).

6. Slipenyuk, A.; Lotsko, D.; Milman, Y.; Kuprin, V.; Yefimov, M.; Danylenko, M. Influence of Scandium on Amorphization of Aluminum Alloys. In Metallic Materials with High Structural Efficiency. NATO Science Series II: Mathematics, Physics and Chemistry; Senkov, O.N., Miracle, D.B., Firstov, S.A., Eds.; Springer: Dordrecht, The Netherlands, 2004; Volume 146. [CrossRef]

7. Røyset, J.; Ryum, N. Scandium in aluminium alloys. Int. Mater. Rev. 2005, 50, 19-44. [CrossRef]

8. Riva, S.; Yusenko, K.V.; Lavery, N.P.; Jarvis, D.J.; Brown, S.G.R. The scandium effect in multicomponent alloys. Int. Mater. Rev. 2016, 61, 203-228. [CrossRef]

9. Awd, M.; Tenkamp, J.; Hirtler, M.; Siddique, S.H.; Bambach, M.; Walther, F. Comparison of microstructure and mechanical properties of scalmalloy ${ }^{\circledR}$ produced by selective laser melting and laser metal deposition. Materials 2018, 11, 17. [CrossRef] [PubMed]

10. Wang, W.; Pranolo, Y.; Cheng, C.Y. Metallurgical processes for scandium recovery from various resources: A review. Hydrometallurgy 2011, 108, 100-108. [CrossRef]

11. European Commission: Critical Raw Materials. Third List of Critical Raw Materials for the EU of 2017. Available online: https:/ / ec.europa.eu/growth/sectors/raw-materials/specific-interest/critical_en (accessed on 26 January 2018).

12. U.S. Geological Survey. Mineral Commodity Summaries, SCANDIUM. January 2016. Available online: https:/ / minerals.usgs.gov/minerals/pubs/commodity/scandium/mcs-2016-scand.pdf (accessed on 23 January 2018).

13. Tomilo, Z.M.; Molchan, P.V.; Shestak, A.S.; Finskaya, V.M.; Prytkova, N.A.; Ustinovich, S.N. Influence of annealing on the superconductivity of $\mathrm{ScNi}_{2} \mathrm{~B}_{2} \mathrm{C}$. Phys. C Supercond. 2001, 361, 95-98. [CrossRef]

14. Geissler, U.; Thomas, S.; Schneider-Ramelow, M.; Mukhopadhyay, B.; Lang, K.-D. Aluminum-scandium: A material for semiconductor packaging. J. Electr. Mater. 2016, 45, 5456-5467. [CrossRef]

15. Schmidtke, K.; Palma, F.; Hawkins, A.; Emmelmann, C. Process and mechanical properties: Applicability of a scandium modified al-alloy for laser additive manufacturing. Phys. Procedia 2011, 12, 369-374. [CrossRef]

16. Schoop, U.; Goharkhay, K.; Klimscha, J.; Zagler, M.; Wernisch, J.; Georgopoulos, A.; Sperr, W.; Moritz, A. The use of the erbium, chromium: Yttrium-scandium-gallium-garnet laser in endodontic treatment: The results of an in vitro study. J. Am. Dent Assoc. 2007, 138, 949-955. [CrossRef] [PubMed]

17. Scandium Investing. Why Scandium Could Be a Huge Opportunity: Commercially Viable Scandium Deposits Are Rare, but There Is Indeed Opportunity in this Market. Investing News Network. 12 April 2017. Available online: http:/ / investingnews.com/daily/resource-investing/critical-metals-investing/scandiuminvesting/scandium-production-the-problem-and-the-opportunity/ (accessed on 23 January 2018).

18. Zhang, B.; Xue, X.; Huang, X.; Yang, H.; Han, J. Study on Leaching Valuable Elements from Bayan Obo Tailings. In Proceedings of the 3rd Pan American Materials Congress; The Minerals, Metals \& Materials Series; Meyers, M.A., Benavides, H.A.C., Brühl, S.P., Colorado, H.A., Dalgaard, E., Elias, C.N., Figueiredo, R.B., Garcia-Rincon, O., Kawasaki, M., Langdon, T.G., et al., Eds.; Springer: Cham, Switzerland, 2017. [CrossRef]

19. Kynický, J.; Cihlářová, H.; Smith, M.; Xu, C.; Chakhmouradian, A.; Reguir, K.; Kempe, U.; Galiová, V. Giant Bayan Obo deposit in China, Part I: The main types of ore REE-Fe-Nb-Sc. Geosci. Res. Rep. 2012, 45, 226-231. Available online: http://www.geology.cz/zpravy/en/detail/zpravy_2011-51 (accessed on 25 January 2018).

20. Kalashnikov, A.; Yakovenchuk, V.N.; Pakhomovsky, Y.A.; Bazai, A.V.; Sokharev, V.A.; Konopleva, N.; Mikhailova, J.A.; Goryainov, P.M.; Ivanyuk, G. Scandium of the Kovdor magnetite-apatite-baddeleyite deposit (Murmansk Region, Russia): Mineralogy, spatial distribution, and potential resource. Ore Geol. Rev. 2016, 72, 532-537. [CrossRef]

21. Scandium International Mining Corp. Nyngan Scandium Project. Available online: http://www. scandiummining.com/s/nyngan.asp (accessed on 25 January 2018).

22. Australian Mines Limited. Sconi Project (Cobalt-Nickel-Scandium). Available online: https:// australianmines.com.au/sconi (accessed on 25 January 2018). 
23. Suss, A.; Kuznetsova, N.V.; Kozyrev, A.; Panov, A.; Gorbachev, S. Specific Features of Scandium Behavior during Sodium Bicarbonate Digestion of Red Mud. Travaux 46. In Proceedings of the 35th International ICSOBA Conference, Hamburg, Germany, 2-5 October 2017.

24. REE Mineralisation in circum-Mediterranean Bauxites. Project EURARE. Available online: http://www. eurare.eu/countries / mediterraneanBauxites.html (accessed on 23 January 2018).

25. Ochsenkühn-Petropoulou, M.; Lyberopulu, T.; Parissakis, G. Direct determination of lanthanides yttrium and scandium in bauxites and red mud from alumina production. Anal. Chim. Acta 1994, 296, 305-313. [CrossRef]

26. Ochsenkühn-Petropulu, M.; Lyberopulu, T.; Parissakis, G. Selective separation and determination of scandium from yttrium and lanthanides in red mud by a combined ion exchange/solvent extraction method. Anal. Chim. Acta 1995, 315, 231-237. [CrossRef]

27. Ochsenkühn-Petropulu, M.; Lyberopulu, T.; Ochsenkühn, K.M.; Parissakis, G. Recovery of lanthanides and yttrium from red mud by selective leaching. Anal. Chim. Acta 1996, 319, 249-254. [CrossRef]

28. Lyberopulu, T. Determination and Recovery of Rare Earths from Bauxites and Red Mud. Ph.D. Thesis, National Technical University of Athens, Athens, Greece, 1996. Available online: https:/ / www.didaktorika. gr/eadd/handle/10442/8817 (accessed on 23 January 2018). [CrossRef]

29. Tsakanika, L.-A. Separation and Recovery of Lanthanides from Red Mud by Use of Selective Extraction and Chromatographic Techniques. Ph.D. Thesis, National Technical University of Athens, Athens, Greece, 2013.

30. Lymperopoulou, T.; Tsakanika, L.-A.; Ochsenkühn, K.-M.; Ochsenkühn-Petropoulou, M. Optimization of Mineral Acids Leaching Process for the Recovery of Rare Earth Elements from Greek Red Mud. In Proceedings of the Book of Abstracts of ERES 2017 Conference (European Rare Earth Resources 2017), Santorini, Greece, 28-31 May 2017; pp. 182-184.

31. Ochsenkühn-Petropoulou, M.T.; Hatzilyberis, K.S.; Mendrinos, L.N.; Salmas, C.E. Pilot plant investigation of the leaching process for the recovery of scandium from red mud. Ind. Eng. Chem. Res. 2002, 41, 5794-5801. [CrossRef]

32. Aluminium of Greece. Member of Mytilineos Group. Available online: http://www.alhellas.com/ (accessed on 23 January 2018).

33. Liu, Z.; Li, H. Metallurgical process for valuable elements recovery from red mud-A review. Hydrometallurgy 2015, 155, 29-43. [CrossRef]

34. Borra, C.R.; Pontikes, Y.; Binnemans, K.; Van Gerven, T. Leaching of rare earths from bauxite residue (red mud). Miner. Eng. 2015, 76, 20-27. [CrossRef]

35. Makanyire, T.; Sanchez-Segado, S.; Jha, A. Separation and recovery of critical metal ions using ionic liquids. Adv. Manuf. 2016, 4, 33-46. [CrossRef]

36. Hatzilyberis, K.; Lymperopoulou, T.; Tsakanika, L.-A.; Ochsenkuehn, K.; Georgiou, P.; Ochsenkuehn-Petropoulou, M. Design Aspects of a Selective Leaching Process for Scandium Recovery from Bauxite Residue. In Proceedings of the Book of Abstracts of ERES 2017 Conference (European Rare Earth Resources 2017), Santorini, Greece, 28-31 May 2017; pp. 188-189.

37. Vaggelatos, I.V. Utilization of Red Mud in the Cement Industry. Ph.D. Thesis, University of Patras, Patras, Greece, 2008. [CrossRef]

38. Gamaletsos, P.N.; Godelitsas, A.; Kasama, T.; Kuzmin, A.; Lagos, M.; Mertzimekis, T.J.; Göttlicher, J.; Steininger, R.; Xanthos, S.; Pontikes, Y.; et al. The role of nano-perovskite in the negligible thorium release in seawater from Greek bauxite residue (red mud). Sci. Rep. 2016, 6. [CrossRef] [PubMed]

39. Coulson, J.M.; Richardson, J.F. Chemical Engineering, 2nd ed.; Pergamon Press: Oxford, UK, 1968; Volume 2, p. §10.2, ISBN 100080131859.

40. Vossenkaul, D.; Stopic, S.; Friedrich, B. Gel Avoidance in Leaching of High Silica Containing Ores-A Case Study for Eudialyte Concentrates. In Proceedings of the Book of Abstracts of ERES 2017 Conference (European Rare Earth Resources 2017), Santorini, Greece, 28-31 May 2017; pp. 28-31.

41. Levenspiel, O. Chemical Reaction Engineering, 3rd ed.; John Wiley \& Sons, Inc.: New York, NY, USA, 1999; p. 390, ISBN 0-471-25424-X.

(C) 2018 by the authors. Licensee MDPI, Basel, Switzerland. This article is an open access article distributed under the terms and conditions of the Creative Commons Attribution (CC BY) license (http:/ / creativecommons.org/licenses/by/4.0/). 